\title{
Desinfecção e acondicionamento de escovas dentais: conhecimento e atitudes de acadêmicos de enfermagem
}

\author{
Disinfection and storage of toothbrushes: \\ knowledge and attitudes of nursing academics
}

\section{Desinfección y acondicionamiento de escobas dentales:} conocimiento y actitudes de académicos de enfermería

\author{
Jamine Orrico COSTA ${ }^{\mathbf{1}}$ \\ Fábio Silva de CARVALHO ${ }^{2}$ \\ Cristiane Alves Paz de CARVALHO ${ }^{3}$ \\ ${ }^{1}$ Cirurgiã-Dentista, Pós-Graduanda na Associação Brasileira de Odontologia, ABO Taguatinga, 71978-190 Taguatinga-DF, Brasil \\ ${ }^{2}$ Doutor em Ciências da Saúde, Professor Adjunto da Universidade Estadual do Sudoeste da Bahia, UESB, \\ Departamento de Saúde I, Curso de Odontologia, CEP: 45208-409, Jequié-BA, Brasil \\ ${ }_{3}^{3}$ Doutora em Ciências da Saúde, Professora Adjunta da Universidade Estadual do Sudoeste da Bahia, UESB, \\ Departamento de Saúde I, Curso de Odontologia, CEP: 45208-409, Jequié-BA, Brasil
}

\begin{abstract}
Resumo
Sabe-se que as escovas dentais são instrumentos muito importantes para remoção do biofilme bacteriano e que microrganismos patogênicos pode contaminá-las. Esse estudo objetivou verificar o conhecimento e as atitudes de estudantes de enfermagem relativo à descontaminação e acondicionamento das escovas dentais. Tratou-se de um estudo transversal, descritivo, realizado com estudantes de enfermagem de uma universidade baiana. A coleta de dados foi feita por meio de um questionário e após, realizou-se análise estatística descritiva. Participaram deste estudo 129 estudantes, matriculados do primeiro ao nono semestre do curso. Constatou-se que 55,0\% possuíam conhecimento sobre desinfecção da escova dental. Quanto à relevância da desinfecção das escovas, aproximadamente 91,0\% afirmaram ser importante, entretanto, 90,7\% disseram não utilizar nenhum antisséptico para realizar a desinfecção da escova. Com relação à periodicidade de troca das escovas, 50,4\% disseram trocar em um período de dois a três meses. Sobre o procedimento que realizam com a escova após o uso, 49,6\% responderam que apenas lavam a escova com água corrente e 37,0\% dos estudantes confirmaram guardar suas escovas dentro do armário do banheiro. Concluiu-se que a maioria dos acadêmicos tem conhecimento e considera importante a desinfecção das escovas dentais. Por outro lado, não utilizam nenhuma substância para promover a desinfecção, não possuem o hábito de secar as cerdas e, portanto, não realizam os procedimentos necessários para que suas escovas dentais fiquem livres de contaminação.

Descritores: Escovação Dentária; Contaminação; Desinfecção.
\end{abstract}

\begin{abstract}
It is known that toothbrushes are very important instruments to remove bacterial biofilm and that pathogenic microorganisms can contaminate them. This study aimed to verify the knowledge and attitudes of nursing students on the decontamination and storage of toothbrushes. This was a cross-sectional and descriptive study, performed with nursing students from a university in the state of Bahia. The data were collected through a questionnaire, and afterwards, a descriptive statistical analysis was performed. 129 students enrolled from first to ninth semester of the course participated of this study. It was verified that 55.0\% had knowledge of toothbrush disinfection. About the relevance of brushes disinfection, approximately $91.0 \%$ reported to be important, however, $90.7 \%$ said they did not use any antiseptic to perform the brush disinfection. Regarding the periodicity of toothbrushes replacement, 50.4\% said that change occurs in a period between two or three months. About the procedure performed with the toothbrush after use, $49.6 \%$ answered that they just wash the brush with water and $37.0 \%$ of students confirmed keeping their toothbrushes in the bathroom cabinet. It is concluded that most academics have aware and consider important the toothbrushes disinfection. On the other hand, they do not use any substance to promote disinfection; they do not have the habit of drying the bristles and therefore do not perform the necessary procedures so that their toothbrushes are free of contamination.
\end{abstract}

Descriptors: Toothbrushing; Contamination; Disinfection.

\section{Resumen}

Los cepillos dentales son instrumentos muy importantes para la eliminación del biofilm bacteriano y que los microorganismos patógenos pueden contaminarlos. El propósito do presente estudio fue verificar el conocimiento y las actitudes de los estudiantes de enfermería relativos a la descontaminación y acondicionamiento de los cepillos dentales. Estudio transversal, descriptivo, realizado con estudiantes de enfermería de una universidad bahiana. La recolección de datos fue realizada por medio de un cuestionario y después, se realizó análisis estadístico descriptivo. Participaron de este estudio 129 estudiantes, matriculados del primero al noveno semestre del curso. Se constató que el 55,0\% poseía conocimiento sobre desinfección del cepillo dental. En cuanto a la relevancia de la desinfección de las escobillas, aproximadamente el 91,0\% afirmó ser importante, sin embargo, el 90,7\% dijo no utilizar ningún antiséptico para realizar la desinfección del cepillo. En cuanto a la periodicidad de cambio de las escobillas, el 50,4\% dijo cambiar en un período de dos a tres meses. En cuanto al procedimiento que realizan con el cepillo después del uso, el 49,6\% respondió que apenas lavan el cepillo con agua corriente y el 37,0\% de los estudiantes confirmaron guardar sus cepillos dentro del armario del baño. Se llegó a la conclusión de que la mayoría dos académicos tienen conocimiento y considera importante la desinfección de los cepillos dentales. Por otro lado, no utilizan ninguna sustancia para promover la desinfección, no tienen el hábito de secar las cerdas y, por lo tanto, no realizan los procedimientos necesarios para que sus cepillos dentales queden libres de contaminación.

Descriptores: Cepillado Dental; Contaminación; Desinfección.

\section{INTRODUÇÃO}

A escova dental é um instrumento fundamental e universalmente aceito para realizar o controle do biofilme, sendo que por meio da escovação dental controlam-se as principais patologias bucais placa dependentes (cárie e doença periodontal). Entretanto, durante a escovação, as cerdas das escovas dentais são contaminadas por microrganismos provenientes da microbiota bucal, onde são encontradas mais de 700 diferentes espécies ${ }^{1}$.

Diversos microrganismos, como bactérias, vírus e fungos provenientes do meio ambiente em que a escova está 
guardada também podem contaminá-la, uma vez que as cerdas das escovas dentais são ambientes propícios para multiplicação de tais agentes patogênicos ${ }^{2,3,4}$.

$\mathrm{Na}$ década de 20 , houve um estudo pioneiro sobre o tema, comprovando que as escovas dentais poderiam ser causadoras de infecções bucais reincidentes ${ }^{5}$. Sendo assim, não é recente a constatação de que as escovas dentais devem ser desinfetadas e devidamente acondicionadas.

Durante a escovação dos dentes pode ocorrer traumatismo na gengiva, que leva à possibilidade de os indivíduos apresentarem uma porta de entrada para microrganismos, o que sinaliza para que as pessoas realizem a desinfecção das escovas dentais. Desta forma, a orientação de profissionais ensinando e motivando seus pacientes quanto à correta higienização e armazenamento de suas escovas dentais é de grande relevância ${ }^{3}$.

Crianças e pacientes imunodeprimidos, devido à baixa imunidade, devem ter cuidado especial com as escovas dentais, uma vez que contaminada com microrganismos a mesma pode servir como veículo para infecção e reinfecção ${ }^{6}$.

Tem sido observado que há uma preocupação do mercado odontológico em desenvolver novos materiais e técnicas e pouca importância tem sido atribuída aos cuidados básicos como o acondicionamento, a troca e a desinfecção das escovas dentais ${ }^{7}$.

Para que a contaminação seja controlada, as escovas devem ser trocadas com regularidade e, principalmente, após qualquer tipo de infecção bucal ${ }^{8,9}$.

É recomendável que depois do uso a escova seja lavada, seca e mantida em ambiente ventilado. Contudo, alguns grupos bacterianos, como Streptococcus mutans conseguem se manter viáveis por até oito horas após a utilização da escova ${ }^{10}$. Portanto, a reinoculação desses microrganismos pode acontecer na próxima escovação ou a contaminação quando as escovas são mantidas juntas ${ }^{1}$; isso significa que deixá-las secar não é suficiente para eliminar os microrganismos ${ }^{4}$. Dessa forma, é preciso além de lavar a escova dental, realizar sua desinfecção ${ }^{11}$. Entretanto, a descontaminação das escovas dentais gera a necessidade de uma etapa a mais durante o procedimento de higienização bucal e isto pode ser um fator que contribua para a não adoção da etapa de desinfecção ${ }^{12}$.

Por esses motivos, pesquisadores avaliaram a contaminação microbiana das escovas dentais, visando propor alguns métodos para desinfecção das mesmas ${ }^{13,14}$. O gluconato de clorexidina $0,12 \%$ foi proposto como um dos antimicrobianos utilizados para a desinfecção de escovas dentais ${ }^{15}$. O hipoclorito de sódio, encontrado no mercado nacional, também possui ação antimicrobiana confirmada unanimemente por pesquisadores e, por apresentar baixo custo e fácil acesso, pode ser utilizado por todas as classes sociais como alternativa caseira na descontaminação das escovas dentais ${ }^{16}$. Dentifrícios contendo agentes antimicrobianos, como o triclosan, quando utilizados para higienização bucal, também têm demonstrado efeito positivo no combate às bactérias das cerdas das escovas ${ }^{17}$.

Apesar de ser uma informação pouco difundida, as escovas dentais devem sofrer desinfecção regularmente e serem acondicionadas em local apropriado, de forma que o cuidado inadequado pode resultar no aumento dos processos infecciosos em dentes e gengivas, principalmente em pacientes imunocomprometidos.

Considerando-se que enfermeiros, assim como profissionais da área de saúde em geral, são importantes atores na saúde pública e potenciais promotores da educação em saúde, o objetivo deste estudo foi avaliar o conhecimento e as atitudes dos estudantes de enfermagem a respeito da desinfecção e acondicionamento da escova dental.

\section{MATERIAL E MÉTODO}

A coleta de dados deste estudo foi realizada somente após sua análise e aprovação pelo Comitê de Ética em Pesquisa da Universidade Estadual do Sudoeste da Bahia - CEP/UESB (CAAE 35464914.2.0000.0055), além das autorizações concedidas pelos participantes, mediante o preenchimento do Termo de Consentimento Livre e Esclarecido (TCLE). Adicionalmente, as pesquisadoras seguiram a Resolução 466/2012 do Conselho Nacional de Saúde, sendo resguardados todos os princípios éticos que norteiam o desenvolvimento de pesquisa científica com seres humanos.

A população deste estudo transversal e descritivo foi composta pelos 205 acadêmicos matriculados do primeiro ao nono semestre do curso de enfermagem da Universidade Estadual do Sudoeste da Bahia, campus de Jequié (UESB - Jequié) durante o primeiro período letivo de 2015.

Para a coleta de dados, foi utilizado um questionário estruturado, de abordagem quantitativa. Inicialmente, o questionário permitiu a caracterização do participante da pesquisa, com informações referentes à idade, sexo e semestre do curso em que estava matriculado. Posteriormente, foram utilizadas algumas questões que permitiram analisar o conhecimento dos acadêmicos sobre a desinfecção e o armazenamento das escovas dentais. $\mathrm{O}$ questionário foi elaborado de acordo com os trabalhos de Zão et al. ${ }^{18}$ e Mialhe et al. ${ }^{19}$.

Os dados foram processados em planilha do programa Office Excel $2016^{\circledR}$.Posteriormente, realizou-se a análise estatística descritiva, baseada em proporções e frequências absolutas e relativas.

\section{RESULTADOS}

Dos 205 estudantes regularmente matriculados no período da coleta de dados desta pesquisa, 76 não estavam presentes nos dias de aplicação dos questionários ou recusaram-se a participar da pesquisa. Desta forma, a amostra final deste estudo foi de 129 estudantes, o que corresponde à taxa de resposta de 63,0\%.

A média de idade dos participantes foi de 22,3 anos, sendo a maioria do sexo feminino $(87,6 \%)$ e pertencente ao quarto semestre do curso $(18,6 \%)$ (Tabela 1$)$.

\begin{tabular}{|c|c|c|}
\hline & $\mathbf{N}$ & $\%$ \\
\hline \multicolumn{3}{|l|}{ Sexo } \\
\hline Masculino & 16 & 12,4 \\
\hline Feminino & 113 & 87,6 \\
\hline \multicolumn{3}{|l|}{ Semestre } \\
\hline 10 & 19 & 14,7 \\
\hline $2^{\circ}$ & 21 & 16,3 \\
\hline $3^{\circ}$ & 13 & 10,1 \\
\hline $4^{\circ}$ & 24 & 18,6 \\
\hline $5^{0}$ & 11 & 8,5 \\
\hline $6^{\circ}$ & 18 & 14,0 \\
\hline $7^{0}$ & 7 & 5,4 \\
\hline $8^{\circ}$ & 14 & 10,9 \\
\hline 90 & 2 & 1,5 \\
\hline Total & 129 & 100,0 \\
\hline
\end{tabular}


Sobre a desinfecção de escova de dente, apesar de a maioria possuir conhecimento $(55,0 \%)$, percentual importante relatou nunca ter ouvido falar sobre este assunto (44,2\%). Quando questionados sobre a relevância da desinfecção de escovas dentais, aproximadamente 91,0\% afirmaram a importância do procedimento e apenas $8,5 \%$ não sabiam (Tabela 2).

Tabela 2. Conhecimento e importância da desinfecção de escovas dentais para estudantes de enfermagem, Jequié-BA, 2015

\begin{tabular}{lrrr}
\hline & & N & \% \\
\hline $\begin{array}{l}\text { Tem conhecimento } \\
\text { desinfecção }\end{array}$ & sobre & & \\
Não & 57 & 44,2 \\
Sim & 71 & 55,0 \\
Sem resposta & 1 & 0,8 \\
Considera importante a desinfecção & & \\
Não & 1 & 0,8 \\
Sim & 117 & 90,7 \\
Não sei & 11 & 8,5 \\
\hline Total & 129 & 100,0 \\
\hline
\end{tabular}

Quanto à periodicidade de troca das escovas se observou que cerca da metade dos estudantes $(50,4 \%)$ trocavam em um período de dois a três meses. Quando indagados sobre o procedimento que realizavam com a escova após o uso da mesma, 49,6\% responderam que lavavam a escova com água corrente. Dentre os que responderam mais de um procedimento, as respostas mais citadas foram: lava a escova em água corrente e passa o dedo nas cerdas $(42,1 \%)$ e lava a escova com água corrente e bate na pia $(26,3 \%)$ (Tabela 3$)$.

Tabela 3. Tempo médio e cuidado após o uso das escovas dentais por estudantes de enfermagem, Jequié-BA, 2015

\begin{tabular}{lrr}
\hline & N & \% \\
\hline Tempo de uso da escova dental & & \\
Menos de 1 mês & 4 & 3,1 \\
2 a 3 meses & 65 & 50,4 \\
3 a 4 meses & 31 & 24,0 \\
5 a 6 meses & 20 & 15,6 \\
6 a 11 meses & 7 & 5,4 \\
Mais de 1 ano & 1 & 0,8 \\
Sem resposta & 1 & 0,8 \\
Cuidados após o uso da escova dental & & \\
Lava com água corrente & 64 & 49,6 \\
Bate na pia & 3 & 2,3 \\
Passa o dedo & 3 & 2,3 \\
Enxuga em toalha de pano & 1 & 0,8 \\
Outros & 1 & 0,8 \\
Mais de uma resposta & 57 & 44,2 \\
Total & 129 & 100,0 \\
\hline
\end{tabular}

Quanto ao uso de algum antisséptico para realização da desinfecção da escova dental, $90,7 \%$ responderam que não utilizavam (Tabela 4). Dentre os que mencionaram o uso, Listerine foi o antisséptico mais utilizado $(41,7 \%)$, seguido por Colgate $(25,0 \%)$, Cepacol $(16,7 \%)$ e Oral B $(8,3 \%)$. Apenas um estudante não especificou o antisséptico utilizado. Sobre o acondicionamento das escovas após o uso, 48 estudantes $(37,2 \%)$ confirmaram guardar suas escovas dentro do armário do banheiro (Tabela 4). Dentre os que mencionaram mais de uma resposta, sete estudantes $(46,7 \%)$ responderam que guardavam suas escovas dentro do guarda roupa, armazenadas ou não dentro de um protetor.
Tabela 4. Uso de antissépticos para a desinfecção e acondicionamento das escovas dentais após o uso, por estudantes de enfermagem, JequiéBA, 2015

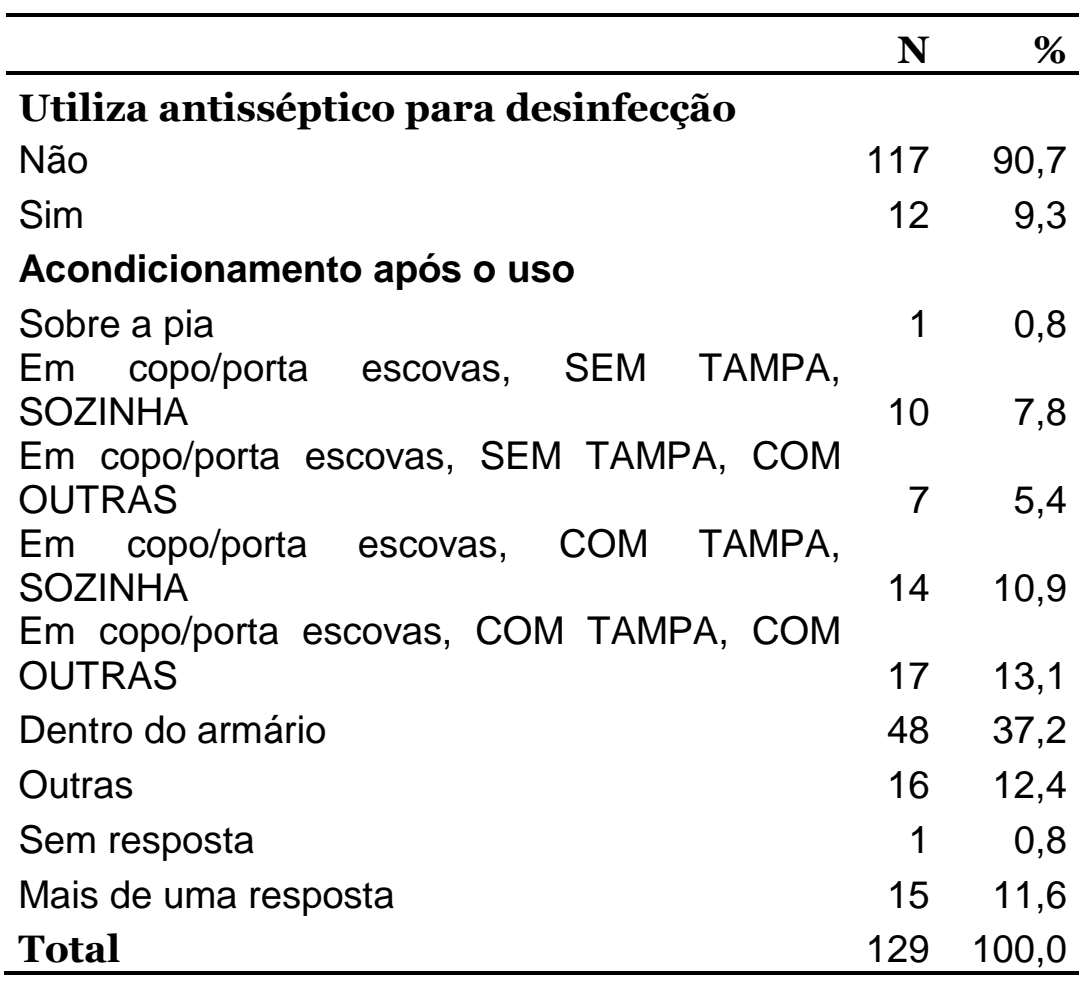

\section{DISCUSSÃO}

As escovas dentais são importantes instrumentos de higiene bucal, entretanto podem exercer importante papel no processo de transmissão de doenças, ao servirem como reservatório de microrganismos ${ }^{20}$. Considerando-se a contaminação das escovas, é imperativo proceder a sua desinfecção desde a primeira utilização para prevenir a formação de biofilme bacteriano nas cerdas até a sua substituição $0^{2,21}$.

Apesar de a maioria dos estudantes de enfermagem deste estudo considerar importante a desinfecção das escovas dentais e ter ouvido falar desse assunto, parcela considerável negou esse conhecimento. Isto sinaliza para a necessidade de ampliar a divulgação dos cuidados quanto à utilização e conservação das escovas dentais, principalmente com relação ao modo correto de desinfetar as mesmas após seu uso.

O tempo médio indicado pelos fabricantes para a troca das escovas dentais é de três meses; contudo, não existe um consenso para este tempo na literatura científica, advertindo-se de que sua substituição aconteça quando as cerdas apresentarem desgastes ${ }^{22}$. De acordo com Nelson Filho et al. $^{2}$ as escovas devem ser substituídas, não apenas devido ao desgaste das cerdas, mas também pelo grau de contaminação que as mesmas adquirem com o tempo ${ }^{2}$. Em estudo realizado por Queiroz et al. ${ }^{12}$ observou-se que $85,2 \%$ dos participantes da pesquisa trocavam suas escovas em um período igual ou inferior a três meses. Neste estudo, observou-se que para a metade dos estudantes de enfermagem a periodicidade da troca das escovas dentais é entre dois e três meses. Vale destacar que parte importante dos estudantes deste estudo relatou utilizar a mesma escova por um período superior a três meses. Isto pode ter algumas implicações como utilizar escovas com as cerdas desgastadas, o que contribui para a deficiência da higiene bucal, ou escovas contaminadas pelo tempo de uso.

O processo de desinfecção da escova se inicia no momento da lavagem e $49,6 \%$ dos participantes afirmaram tão somente lavar a escova com água corrente após seu uso. No entanto, isoladamente, esta não parece ser a melhor conduta para evitar a contaminação. É recomendável que depois do uso a escova seja lavada, seca e mantida em 
ambiente ventilado $^{10}$. Verificou-se que $42,1 \%$ dos acadêmicos confirmaram passar o dedo nas cerdas da escova no momento do enxágue, o que pode contaminar a escova com microrganismos do tipo Staphylococcus ${ }^{18}$.

Estudo desenvolvido por Zão et al. ${ }^{18}$ demostrou que menos de $20 \%$ dos acadêmicos avaliados empregavam algum tipo de antisséptico para realização da desinfecção das escovas dentárias. Este percentual, apesar de baixo, foi ainda maior que o encontrado no presente estudo, onde menos de $10 \%$ da amostra empregava algum tipo de produto. Considera-se este dado preocupante, visto que a não descontaminação da escova dental, representa um risco potencial à saúde ${ }^{11}$. Vários agentes químicos para desinfecção de escovas dentais têm sido apontados na literatura científica, dentre eles a clorexidina a $0,12 \%$. Esta é praticamente atóxica e seu uso proporciona extrema segurança. Entretanto, a mesma tem o custo elevado, quando comparado a outros antimicrobianos, como o hipoclorito de sódio a $1 \%$. Um recurso alternativo e econômico para realização da desinfecção das escovas dentais é borrifar antissépticos bucais nas cerdas usando um borrifador, pois desta forma a família toda pode utilizar o mesmo frasco. Todavia os antissépticos considerados como mais eficazes pelos autores foram à base de gluconato de clorexidina na concentração $0,12 \%$, que têm o custo elevado. Devido a isso, é importante considerar outras alternativas para a desinfecção das escovas dentais, como por exemplo o hipoclorito, que as pessoas comumente têm em sua casa e pode facilitar a adesão aos protocolos de desinfecção dentária ${ }^{15}$. Outra opção para a desinfecção das escovas dentais seria deixar a escova imersa em água fervente por dez minutos. Esse método é eficiente e pode ser utilizado caso a pessoa não tenha acesso às outras soluções ${ }^{11}$.

Estudo realizado por Nelson-Filho et al. ${ }^{2}$ apontou que a escova não deve permanecer sobre a pia do banheiro, pois é o local mais contaminado da casa. Pesquisa comprovou a presença de coliformes fecais alojados em escovas, em decorrência das descargas realizadas, bem como da proximidade com o vaso sanitário ${ }^{18}$.

Diante disso, alguns autores recomendam que o melhor é guardar a escova desinfetada dentro do armário do banheiro $^{2}$, local em que menos de $38,0 \%$ dos entrevistados deste estudo armazenam suas escovas. Por outro lado, há algumas controvérsias em relação ao armazenamento da escova no armário do banheiro. Mialhe et al. ${ }^{19}$ relataram que o armário do banheiro não é o local mais adequado para guardar as escovas dentais, nem as caixas e protetores de cerdas, por serem um ambiente úmido e quente, que favorece o crescimento microbiano. Os autores relataram ainda que o armário do banheiro pode favorecer a contaminação cruzada, pois frequentemente várias escovas ficam armazenadas juntas, com as cerdas em contato umas com as outras ${ }^{19}$. Isso comprova que os participantes da pesquisa que relataram armazenar suas escovas, juntamente com outras, estão armazenando de forma equivocada. Portanto, é recomendável após lavar a escova, remover o excesso de água e guardar em ambiente seco e ventilado. É preciso lavá-las e desinfetá-las todos os dias ou uma vez por semana, não as secar em toalha de banho, rosto ou papel higiênico ${ }^{11}$

Diante do exposto, ressalta-se que a higienização das escovas deve estar inserida no contexto da prevenção e educação em saúde bucal e a divulgação da prática correta de acondicionamento e de desinfecção das mesmas é de suma importância para que a população em geral conheça e possa adotá-las.

\section{CONCLUSÃO}

Apesar de apresentarem bom conhecimento e considerarem a desinfecção das escovas dentais importante, a maioria dos acadêmicos de enfermagem não utiliza nenhuma substância para promover a desinfecção e não possui o hábito de secar as cerdas antes de armazená-las. Portanto, não realiza os procedimentos necessários para que suas escovas dentais fiquem livres de contaminação, seja por falta de informação ou, na maioria dos casos, por descaso em relação à gravidade da situação, já que muitos reconhecem a importância da desinfecção, embora não a realizem.

Dessa maneira, verifica-se que há necessidade de desenvolvimento de programas de educação e promoção de saúde, a fim de esclarecer os riscos da contaminação das escovas dentais aos demais profissionais de saúde e à população em geral, além de orientá-los quanto às medidas profiláticas acessíveis, com a finalidade de promover melhoria na saúde bucal da população.

\section{REFERENCIAS}

1. Beneduce C, Baxter KA, Bowman J, Haines M, Andreana S. Germicidal activity of antimicrobials and VIOlight personal travel toothbrush sanitizer: an in vitro study. J Dent. 2010; 38(8):621-5.

2. Nelson Filho P, Faria G, da Silva RA, Rossi MA, Ito IY. Evaluation of the contamination and disinfection methods of toothbrushes used by 24-to 48-month- old children. J Dent Child. 2006; 73(3):152-8.

3. Ankola AV, Hebbal M, Eshwar S. How clean is the toothbrush that cleans your tooth? Int J Dent Hyg. 2009; 7(4):237-40.

4. Chibinski ACR, Grando K, Fanchin PT, Campagnoli E, dos Santos FA, Wambier DS. Descontaminação de escovas dentais utilizadas por crianças portadoras de necessidades especiais: análise microbiológica. RSBO. 2011; 8(2):145-52.

5. Carolus M, Cobb MD. The toothbrush as a cause of repeated infections of the mouth. Boston Med Surg J.1920; 183:263-4.

6. Siqueira Júnior HM, Reis JRG, Toledo Júnior EG, de Andrade PF, Diniz CG, Salgado IO. Os microorganismos contaminam as escovas dentais? HU Rev. 2011; 37(4):409-12.

7. Nelson Filho P. FORP realiza estudo sobre importância da higienização de escovas de dente. [Internet]. 1999. [acesso em 2014 jun 15]. Disponível em: http://www. jornaldosite.com.br/materias/pesquisa\&tecnologia/anter iores/edicao146/pesquisa14610.htm

8. Balappanavar AY, Nagesh L, Ankola AV, Tangade PS, Kakodkar P, Varun S. Antimicrobial efficacy of various disinfecting solutions in reducing the contamination of the toothbrush - a comparative study. Oral Health Prev Dent. 2009; 7(2):137-45.

9. Pai V. Effect of a single-use toothbrush on plaque microflora. Indian J Dent Res. 2009; 20(4):404-6.

10. Saravia ME, Nelson-Filho P, da Silva RA, Faria G, Rossi MA, Ito IY. Viability of streptococcus mutans toothbrush bristles. J Dent Child. 2008; 75(1):29-32.

11. Santos, R. Pesquisa sugere que escova de dente é um dos grandes alvos das bactérias e fungos. APCD Jornal. [Internet]. 2011. [acesso em 2014 jun 15]. Disponível 
em: http://rossiodontologia.com.br/noticias/pesquisasugere-que-escova-de-dente-e-um-dos-grandes-alvosdas-bacteria

12. Camargo RA, Schimim SC, Alves FBT, Chibinski ACR. Avaliação microbiológica da efetividade de uma escova antibacteriana: um estudo in vivo. Rev Odontol Unesp. 2013; 42(1):54-8.

13. Sato S, Ito IY, Lara EH, Panzeri H, Albuquerque Junior RF, Pedrazzi V. Bacterial survival rate on toothbrushes and their decontamination with antimicrobial solutions. J Appl Oral Sci. 2004; 12(2):99-103.

14. Teitelbaum AP, Thomassewski MH, Mansur MEC, Sabbagh-Haddad A, Wambier DS, Czlusniak GD et al. Contaminação de escovas dentais usadas em crianças com autismo. J Health Sci Inst. 2008; 26(1):111-4.

15. Soares DGS, Oliveira CB, Leal C, Drumond MRS, Padilha WWN. Atividade antibacteriana in vitro da tintura de aroeira (Schinusterebinthifolius) na descontaminação de escovas dentais contaminadas pelo S. mutans. Pesq Bras Odontopediatira Clín Integr. 2007; 7(3):253-7.

16. Araújo MS, Thedei Júnior G, Carneiro WJ, Lobato SMP. Descontaminação de escovas dentais: desenvolvimento e padronização de método para uso doméstico. J Bras Clin Odontol Integr. 2006; 10(52):71-9.

17. Goldsmith RN, Shey Z, Houpt MI, Fine D, Schreiner $\mathrm{H}$, Greenberg B. Toothbrush bristle wear and bacterial adherence. Pediatr Dent. 2007; 29(3):243-7.

18.Zão ÉJR, da Silva MAM, Alves MU. Desinfecção e armazenamento de escovas dentais: avaliação da prática realizada por acadêmicos do curso de odontologia da Universidade Severino SombraVassouras/RJ. Rev Pró-univerSUS. 2011; 2(1):53-64.

19. Mialhe FL, Silva DD, Possobon RF. Avaliação dos cuidados relativos ao armazenamento e desinfecção das escovas dentais por acadêmicos de odontologia. Rev Odontol Unesp. 2007; 36(3):231-5.

20. Frazelle MR, Munro CL. Toothbrush contamination: a review of the literature. Nurs Res Pract. 2012; 2012:420630

21. Efstratiou M, Papaioannou W, Nakou M, Ktenas E, Vrotsos IA, Panis V. Contamination of a toothbrush with antibacterial properties by oral microorganisms. J Dent. 2007; 35(4):331-7.

22. Queiroz FS, Nóbrega CBC, Costa LED, Reul MA, Abreu RSA, Leite MS. Avaliação do perfil de armazenamento e descontaminação das escovas dentais. Rev Odontol Unesp. 2013; 42(2):89-93.

23. Nelson Filho P, Oliveira-Neto JM, Faria G, Ruviére DB, Silva RAB. Avaliação dos conhecimentos de alunos de graduação em odontologia e de cirurgiões dentistas relativos aos cuidados com as escovas dentais, após sua utilização. IAES-Revista da Faculdade de Odontologia do Instituto Amazônia de Ensino Superior 2004;1.

\section{CONFLITO DE INTERESSES}

Os autores declaram não haver conflitos de interesse.

\section{AUTOR PARA CORRESPONDÊNCIA}

\section{Cristiane Alves Paz de Carvalho}

capcarvalho@uesb.edu.br

Submetido em 30/06/2017

Aceito em 10/08/2017 